\title{
5. CAMINO Y DISCUSIONES DE LA HERMENÉUTICA ANALÓGICA
}

\section{INTRODUCCIÓN}

En lo que sigue me interesa aclarar la hermenéutica analógica señalando el camino que he seguido hasta ella. Se debe al aprecio que aprendí a tener a la noción de analogía, a la doctrina analógica, que recorre la historia, pero que tiene como uno de sus grandes adalides a santo Tomás de Aquino. Él hizo que la analogía fuera la doctrina de la orden dominicana, a la cual perteneció, en contra de los franciscanos escotistas, que fueron univocistas, y en contra de los jesuitas suarecianos, que privilegiaron la analogía de atribución a despecho de la analogía de proporcionalidad, pese a que el Aquinate usaba las dos.

Vienen luego algunas discusiones acerca de la hermenéutica analógica, reseñando las cuales creo y espero que se volverá más claro lo que deseo desarrollar en dicha hermenéutica analógica. Muchas veces en las discusiones hay incomprensión y equívoco, pero otras tantas hay algo que aprender y aprovechar de lo que se nos dice. Con ese espíritu quiero recorrerlas. 


\section{ITINERARIO (O DERIVA) HACIA LA ANALOGÍA}

Me interesó la noción de analogía porque es la base de la doctrina de mi orden, la de los dominicos, y se estudiaba mucho en la filosofía y en la teología tomistas, es decir, orientadas en la línea de santo Tomás de Aquino. Ha sido nuclear en la doctrina de la Orden dominicana (Beuchot, 2008c, pp. 105 y ss.). Tuve que estudiar mucho ese tema, tanto en mi formación filosófica como teológica, y me pareció que era algo muy rico. De hecho, por eso, le puse el nombre de Analogía a la revista filosófica que fundé, dentro de la Orden, en 1987.

En mis años de formación, influyeron en mis afanes por la analogía algunos profesores tomistas que tuve en mis estudios filosóficos en México, sobre todo, el dominico mexicano Rafael Ávalos. Él me orientó a la lectura de la obra del dominico español Santiago Ramírez sobre la analogía. Esta última obra, en cuatro tomos, contenía mucha información sobre la historia de ese concepto y sobre el uso que se le dio en la escuela tomista. Ávalos también me recomendó estudiar a Francisco de Araújo, dominico español del siglo XVII, el cual me llevó al cardenal Cayetano, dominico del siglo XVI. Aprecié mucho la obra de Cayetano Sobre la analogía de los nombres, a pesar de que Ralph McInerny considera que se apartó de santo Tomás. Leí las obras de este tomista estadounidense, y lo conocí cuando coincidimos en la Pontificia Academia de Santo Tomás de Aquino, en el Vaticano, en 2006 y, a pesar de nuestras pláticas, nunca estuve totalmente convencido de la traición de Cayetano.

Uno de los que me hizo ver la importancia de la noción de analogía en la filosofía fue el dominico polaco, tomista y gran lógico matemático I. M. Bochenski, en la Universidad de Friburgo, Suiza. Él trataba de formalizar lógicamente la analogía, de construir un 
formalismo lógico para sujetarla a la lógica matemática. Perteneciente a la escuela de Lukasiewicz, Bochenski se había hecho dominico, y por lo mismo tomista, y aplicaba los instrumentos lógico-matemáticos a esa doctrina filosófica. Después de haber trabajado en la lógica de la analogía, desde los años cuarenta, la aplicaba a la filosofía de la religión, hasta su muerte, en 1995. Se ve, sobre todo, en su artículo “On Analogy”, de 1948 (pp. 474 y ss.), y en su libro The Logic of Religion, de 1965 (1975, pp. 158 y ss.). Yo lo tuve de profesor en Friburgo en 1973-1974, y capté la importancia que daba a la noción de la analogía, lo cual me hizo comprender que tenía que ser algo fundamental para la filosofía.

Cuando trabajé en el Instituto de Investigaciones Filosóficas, de la Universidad Nacional Autónoma de México (de 1979 a 1991), que estaba claramente en la línea de la filosofía analítica, varias veces quise retomar el tema de una lógica de la analogía, o lógica analógica, en pos de Bochenski, pero solo me quedé en los estudios históricos, preparatorios para ello (Beuchot, 1987a, pp. 87 y ss. y 1987b, pp. 5 y ss.). Por eso, cuando pasé al Instituto de Investigaciones Filológicas, de esa misma universidad (en 1991), y algunos de allí me pidieron que les diera método, pensé en la hermenéutica, y dejé la lógica, para pensar en hacer, en lugar de una lógica analógica, una hermenéutica analógica. Se trataba de una hermenéutica vertebrada con la noción de analogía. Evitando una hermenéutica unívoca, para la que solo habría una sola interpretación válida, y evitando asimismo una hermenéutica equívoca, para la que prácticamente todas las interpretaciones serían válidas; una hermenéutica analógica, basada en la analogía de proporcionalidad, podía aceptar varias interpretaciones como válidas, más de una pero no todas; y, por la analogía de atribución, escalonadas de mejor a peor, de modo que hubiera una que fungiera como analogado principal y otras como analogados 
secundarios, en orden descendente, hasta un punto en el que ya las interpretaciones fueran inválidas.

También debo a Bochenski mi interés por Charles Sanders Peirce. Él lo usaba mucho para plantear su curso de Lógica desde la semiótica. En sus apuntes vi eso y aprendí la importancia de Peirce. En México me he dedicado bastante a Peirce. Con el tiempo encontraría que para Peirce la analogía era la iconicidad, o estaba conectada con ella. De modo que después incorporé la iconicidad peirceana a la analogía tomista, y obtuve casi lo mismo: una analogía o iconicidad de orden metonímico y otra de orden metafórico, pues, el ícono, para Peirce, se divide en imagen, diagrama o metáfora. La imagen es metonímica, y por otro lado está la metáfora, y el diagrama se mueve entre ambos. De este modo, comencé a hablar de una hermenéutica analógico-icónica.

Otro que me hizo ver la importancia de la analogía fue Paul Ricoeur. Tanto en su libro La simbólica del mal (1960), donde señala el carácter analógico del símbolo, como en su libro La metáfora viva (1975), donde señala el carácter analógico de la metáfora. También habla de la estructura metafórica del símbolo, con lo que capté más a las claras el mismo carácter analógico del símbolo. Pude hablar con Ricoeur en 1987, en un congreso en Granada sobre él y con él, y me confirmó esa importancia de la analogía para la interpretación de los símbolos y las metáforas. Él se basaba mucho en Jakobson, y juntando algo que dice Octavio Paz, y que se repite en Ricoeur, alcancé a intuir que la analogía tenía como dos caras, o dos brazos, la metáfora y la metonimia. Por lo tanto, una hermenéutica analógica serviría de gradiente para oscilar entre esos dos polos.

Pero también, mucho después, ya a finales de la primera década de 2000, encontré una presencia de la dialéctica en la analogía. Ya había visto intentos de conectar la analogía con la dialéctica, o de 
desentrañar el carácter analógico de la dialéctica, o la presencia de la dialéctica en la analogía, pero no había profundizado en ellos. Esto ocurrió por influencia de Dussel y Scannone.

Una de las cosas que me hicieron ver la importancia de la analogía fue la lectura de un artículo de Enrique Dussel (1973, pp. 125 y ss.), y a quien conocí al año siguiente, 1974, en México. La trataba en forma de dialéctica, como analéctica. También hablaba de la analogía Wolfgang Strobl (1963, pp. 54 y ss.), quien cita a Lakebrink y a Beck, solo que la ponía en contra de la dialéctica, y decía que la dialéctica provenía de no conocer la analogía, y que la analogía debía usarse en lugar de la dialéctica, para evitar usarla a esta última. También me ayudó el comentario de un colega mío, dominico, Jorge Íñiguez, que también había estudiado en Friburgo, y que contó que uno de sus maestros, Philibert Secretan, había dicho que la dialéctica era una de las formas de la analogía (de hecho, él había estado en contacto con Dussel, quien colaboró en un volumen colectivo organizado por él) (Secretan y Gisel, 1962).

Por este tiempo sucedió algo curioso. Un colega mío, dominico, Julián Pablo Fernández, era muy amigo de Octavio Paz. Coincidimos en el Centro Universitario Cultura en 1975-1976. Por esas fechas, le comentó de mi interés en la analogía, y me dijo que don Octavio quería hablar conmigo sobre la analogía. Fue un placer conversar con él sobre este tema, aunque, claro está, a él le interesaba más por el lado literario que por el filosófico. Pero me hizo ver la importancia de la analogía para la poesía, abarcando como dos caras suyas la metáfora y la metonimia, cosa que se refleja en su libro Los hijos del limo, de 1990.

Mucho después conocí a Juan Carlos Scannone (1972, pp. 107 y ss.), quien utiliza también la analéctica. Conocí a Scannone a mediados de los noventa. Con él caí en la cuenta de la necesidad de estudiar 
la relación entre analogía y dialéctica. Además de las conversaciones personales, tuve varios diálogos públicos con Scannone, en el filosofado de los jesuitas en Buenos Aires, siempre sobre la analogía y la dialéctica (Beuchot, 2007, pp. 179 y ss. y $2009 a$, pp. 75 y ss.). Él reconoció la hermenéutica analógica, que yo desarrollaba, como propuesta en sus clases de filosofía latinoamericana en la Universidad Gregoriana de Roma (hoy se da una clase sobre hermenéutica analógica en ella, dada por el jesuita dominicano Pablo Mella).

El propio Scannone me habló del trabajo de otro jesuita, José Gómez Caffarena (1960, pp. 143 y ss.), sobre la analogía y la dialéctica. Yo ya conocía a Caffarena. En varias ocasiones hablé con él. Conversamos, entre otras cosas, obviamente, de la analogía, pero no sobre su dialecticidad. Él había señalado una presencia de la dialéctica en la analogía, en la línea de los que hablaban de la analéctica (Lakebrink, Beck, López Quintás, Puntel, Scanonne y Dussel).

En su artículo, Caffarena señala que en el propio Tomás de Aquino se puede encontrar esa dialecticidad de la analogía, por la influencia del Pseudo-Dionisio. Este último pone un momento de afirmación, otro momento de negación y un tercer momento de supereminencia, que parece coincidir con la Aufhebung hegeliana (la superación, reconciliación o síntesis).

De Caffarena recibí esa idea de que la analogía posee cierta dialecticidad ya en sus orígenes tomistas, y debía resarcirla para que fuera más útil y rendidora, para tener que ver con el devenir, con el fieri, el movimiento, la vida.

Otro que me mostró la fuerza analógica de la analogía fue el propio Juan Carlos Scannone. Él la tomaba directamente del brasileño Bruno Puntel, que la señalaba sobre todo en el viejo Schelling. Scannone me dijo que él había pasado a Dussel la idea de la relación 
entre analogía y dialéctica al prestarle el libro de Lakebrink sobre la analéctica. De hecho, Lakebrink se hizo famoso con un libro sobre santo Tomás y Hegel, en el que señalaba el carácter dialéctico de la analogía, y el carácter analógico de la dialéctica, lo mismo que hacía Heinrich Beck y, por otro lado, Puntel (Lakebrink, 1955; Beck, 1968; Puntel, 1969). El propio Puntel veía la dialectización de la analogía como una forma de insertar en ella la historicidad, el tiempo, el movimiento, la vida.

Enrique Dussel, quien la llama, a veces, analéctica y otras anadialéctica, en todo caso la analogía como dialéctica, toma muy en cuenta a Lévinas, quien (siguiendo a Rosenzweig) hace la crítica a Hegel de que su dialéctica se cierra en la totalidad, en la inmanencia, y que no sale al infinito, a la trascendencia. Por eso, Dussel usa la analogía para roturar la dialéctica, para hacerla estallar, para que sea una dialéctica abierta, no concluida y cerrada. El mismo Dussel me ha dicho que, más allá de Hegel, la mejor fuente de inspiración para la analogía dialéctica es el Schelling viejo.

Por eso, no me extrañó que, hablando en una ocasión con Félix Duque, en un congreso en el estado de Nueva York, en 2002, él me comentara que yo tenía que darle movimiento a la analogía, a la hermenéutica analógica, para que no se quedara demasiado estática, para que abrazara al devenir, como pedía Nietzsche, y había tratado de hacer Heidegger al conectar el ser con el tiempo. Era una forma de darle historicidad a la analogía, a la ontología, de hacerla viva. Duque es, entre otras cosas, un buen especialista en Hegel y el idealismo alemán, por lo que me fue significativo su consejo.

La utilización de la analéctica, por parte de López Quintás, no ha sido tan presente en mi obra. Él la emplea, por ejemplo en su Metodología de lo suprasensible, de 1963. A él pude conocerlo hasta 2010, y le pregunté acerca del papel de esa noción en su pensamiento, pero 
me dijo que solo había sido muy fugaz, en ese momento efímero. Así que no pude profundizar en el uso que él da a esa noción.

Otro de mis amigos, Klaus Hedwig (2010, pp. 3 y ss.), ha criticado la analéctica. En cambio, otro amigo, Andrés Ortiz-Osés (2008, pp. 185 y ss.), me ha instado a dialectizar la analogía (Beuchot, 2008b, pp. 191 y ss.). Otros han sido Napoleón Conde, que trabaja en una hermenéutica analógico-dialéctica, y Mario Magallón, que ha visto con buenos ojos la dialectización de la analogía para ser usada en la filosofía mexicana y latinoamericana; más aún, que ha considerado la hermenéutica analógica como un producto de la filosofía mexicana y latinoamericana, y ha visto con agrado su dialectización.

\section{DEBATES}

Me tocó dialogar con Raimon Panikkar cuando hizo una intervención desde el público en el panel "Teología e interculturalidad”, en el Primer Congreso Mundial de Filosofía Intercultural, en la Universidad Pontificia de México, el 7 de marzo de 1995. Con fuerte equivocismo me dijo que si uno no nace en una cultura no puede entender los símbolos de esta. Le dije que podía hacerlo por analogía, pero no parece haberlo aceptado. Aún más, en un libro suyo, tres años después, de 1998, parece responderme cuando uno de sus capítulos se intitula "Es un discurso polisémico que no puede ser ni siquiera analógico", con lo cual cerraba la capacidad del ser humano de entrar un poco a los símbolos de otras culturas, al diálogo intercultural (Panikkar, 1998, p. 30).

En febrero de 1996, tuve un diálogo con Emerich Coreth, en la Facultad de Filosofía de la Universidad Pontificia de México (Beuchot, $1996 a$, pp. 219 y ss). Él reconoció la vigencia de la analogía, 
que había desplegado en su libro Metafísica (1961). Pero dijo que, después de su libro Cuestiones fundamentales de bermenéutica (1969), había abandonado esta disciplina y se había acercado a la pragmática, que era lo que se cultivaba en ese momento en la cultura alemana, de la mano de Apel y Habermas.

Eugenio Trías reveló, en su libro La edad del espiritu (1994), la presencia de la metáfora en el pensamiento posmoderno. Yo le señalé que se necesitaba también la metonimia, la cual hacía juego con la metáfora en el seno de la analogía (Beuchot, 1997, pp. 271 y ss.). Él reconoció ese carácter abarcador de la analogía, y me dijo que mi hermenéutica analógica era muy semejante a su filosofía del límite. Esto me lo dijo en alguna de las veces que vino a México por aquellos años, antes de su enfermedad. Por lo menos, la analogía tiene un carácter de límite, pues, pretende limitar a la univocidad y, sobre todo, a la equivocidad (de modo que la analogía puede considerarse como una equivocidad limitada, como una equivocidad con límites). En 1999, me invitó a dialogar con él en un evento en Madrid, en la Residencia de Estudiantes que estaba dentro del Consejo Superior de Investigaciones Científicas. Allí, cuando él manejaba las nociones de limítrofe y fronterizo, yo añadí en mi ponencia la de mestizo, como analógica, y a él le pareció interesante e importante.

Con Gianni Vattimo discutí en 2004, en una mesa redonda en la Facultad de Filosofía y Letras de la Universidad Nacional Autónoma de México. Él presentó su discusión en la conferencia “¿Hermenéutica analógica o hermenéutica anagógica?” (Vattimo, 2005, pp. 213 y ss.; Beuchot, Vattimo y Velasco, 2006, pp. 21 y ss.). En ella señalaba que la hermenéutica analógica funciona, y es una hermenéutica débil, no prepotente y monolítica. Pero me pedía aceptar más la equivocidad, ser más equívoco, porque veía a la hermenéutica analógica demasiado preocupada por la verdad y la objetividad. En 
cambio, él, como heideggeriano, quería una verdad como aletheia, como desencubrimiento, y proyectada hacia el futuro, como la de Heidegger. Por eso, hablaba de la anagogía, no entendida como sentido místico, sino como del futuro, en la esperanza política. Era cuando comenzaba a volver a la Izquierda, así como había vuelto al cristianismo. En mi respuesta le contesté que, de todos modos, era importante buscar la verdad y la objetividad, para defender el realismo y evitar el relativismo (Beuchot, 2006a, pp. 51 y ss.).

En esa misma ocasión intervino en la discusión el filósofo mexicano Ambrosio Velasco (2006, pp. 43 y ss.), quien recalcó lo que decía Vattimo, que la hermenéutica analógica no buscara tanto la verdad como la creatividad, el descubrimiento, la heurística. A lo cual respondí que la heurística debe servir para buscar mejor la verdad (Beuchot, 2006b, pp. 55 y ss.).

Con Jean Grondin dialogué en 2007. En su conferencia, Grondin sostenía que yo debía tender más a la univocidad, ya que en ella se da la interpretación definitiva, que es la que todos buscamos acerca de cualquier texto. Al revés de Vattimo, que me instaba a aceptar más la equivocidad, Grondin me pedía acercarme más a la univocidad, ya que todos pretendemos la interpretación exhaustiva de cualquier cosa (2008, pp. 521 y ss.; Blanco, 2009, pp. 21 y ss.). Yo contesté en mi réplica que la interpretación unívoca es ciertamente un ideal, incluso un ideal regulativo, pero que no pasa de ser eso, un ideal, y que las más de las veces tenemos que contentarnos con una interpretación solo analógica, aproximativa, y evitar con todas nuestras fuerzas la interpretación equívoca (Beuchot, 2009f, pp. 36-41).

Aunque ha habido muchas otras discusiones, quiero referirme, finalmente, a una discusión parecida con Raúl Alcalá y con Carlos Pereda. De modo semejante a Grondin, piden que me acerque a la univocidad. Alcalá dice que la necesidad de interpretación unívoca, 
en ciertas ocasiones, marca límites a la hermenéutica analógica, y que no toda interpretación tiene que ser analógica (Alcalá, 2009, pp. 103 y ss.). Le respondí que no pretendo universalizar la analogía, sino plantearla para muchos casos, como se dan en las ciencias humanas o humanidades (Beuchot, 2009c, pp. 107 y ss.). Algo parecido ocurrió en 2011 con Pereda, quien me ponía ejemplos en los que no se puede permitir una interpretación analógica, como en la hora de salida de un avión o la receta de una medicina. Si no interpreto unívocamente la hora de salida del avión, me quedaré en tierra, y si el boticario no interpreta unívocamente una receta, no me dará la medicina que necesito. Pero allí es muy claro que no se puede aplicar la hermenéutica analógica. Yo le contesté que, en una ocasión, me hablaron de un posgrado en contaduría, y me dijeron que querían aplicar mi hermenéutica analógica a la contabilidad, y que yo respondí: "Mejor no", pues, podemos imaginarnos cómo podrán ser unas cuentas analógicas, o metafóricas. Claro que esa aplicación tiene sus límites.

En el caso de Guillermo Hurtado, se ha dado tanto la discusión por preferir la univocidad como por preferir la analogía de atribución (Hurtado, 2010, pp. 51 y ss.). Procedente de la filosofía analítica, Hurtado insiste en que se debe tender a la univocidad; y, estudioso de Suárez, piensa que la analogía de atribución corre menos riesgo que la de proporcionalidad de escurrirse a la equivocidad. Me parece que la de proporción también es necesaria, sobre todo, por esa polaridad que tiene de metonimia y metáfora. Por otra parte, Hurtado ha reconocido que la hermenéutica analógica es un movimiento importante dentro de la filosofía mexicana (Hurtado, 2003, pp. 9 y ss.).

Se han dado muchas discusiones más, pero solamente he entresacado algunas, para no ser prolijo y para hacer ver por dónde han 
ido las críticas. Curiosamente, se colocan entre el univocismo y el equivocismo, es decir, los que la atacan desde la univocidad, por falta de pretensiones de claridad, y los que la atacan desde la equivocidad, por considerar que, indebidamente, se preocupa demasiado por la verdad y la objetividad. Yo creo que eso es buena señal, y que nos muestra la fecundidad de la hermenéutica analógica por la naturaleza de la analogía misma.

No se trata de condescender con los que le exigen más aproximación a la univocidad o los que se la exigen hacia la equivocidad. La analogía tiene su propio estatuto. Desde él se defiende de caer demasiado en un polo o en el otro. Es la phrónesis, la prudencia, la que, con su proporción, la hace oscilar entre ambos, sin caerse en ninguno. Esa es la gracia y la función de la analogía.

Lo que sí me queda claro es la necesidad que tenemos en la filosofía de hoy de ir más allá de la univocidad y la equivocidad, en cuya lucha estamos atorados. Es la lucha de siempre. Como decía Borges, de otra lucha, "cambian los rostros, cambian los nombres", pero en toda la historia de la filosofía se ha librado esta guerra, la de los que pugnan por una exactitud ideal, y la de los que se sienten derrotados por la inexactitud y se abandonan a ella. Pero también se dan, entre esos clamores, los que buscan el equilibrio proporcional, que no ideal, sino humano, asequible y, sobre todo, suficiente.

\section{CONCLUSIÓN}

Reconocemos el proceso y la trayectoria de la hermenéutica analógica, tanto en sus orígenes como en algunas de las discusiones que se le han hecho. En cuanto a la trayectoria, he tratado de exponer a las personas que más me han influido para esa propuesta filosófica. 
Han sido varias, y siempre en conexión con el estudio de la analogía. Algunos simplemente por la enseñanza que me hicieron de ese concepto, dentro del aristotelismo-tomismo. Otros por su destacada investigación en cuanto a ese concepto, ya sea por la erudición al exponer su historia, ya sea por su afán de presentar su utilidad en los tiempos actuales. Sobre todo, al tratar de insertarla en la lógica contemporánea, que fue lo que me movió a tratar de incorporarla a la hermenéutica de hoy.

También he procurado registrar algunas de las discusiones e incluso polémicas que se han dado en torno a la hermenéutica analógica. Algunas de ellas han sido muy constructivas, y me han ayudado tanto a desarrollar su construcción sistemática y teórica como sus aplicaciones prácticas. Siempre es muy propia de la filosofía la discusión, y la hermenéutica analógica ha desarrollado un diálogo muy fructífero durante varios años. Espero que la ganancia y el fruto de este se vea en los adelantos y avances que va estructurando esta propuesta. 
